\title{
0 protagonismo das trabalhadoras rurais no acesso ao direito à terra, permanência e modo de produção coletiva
}

\author{
The protagonism of women rural workers in access to the land rights, permanence and \\ collective production approach
}

\section{Ines Terezinha Pastorio* Marli Renate Von Borstel Roesler**}

\begin{abstract}
Resumo:
Este artigo integra a pesquisa dissertativa intitulada A Mulher no Processo Produtivo Familiar com Sustentabilidade no Assentamento Valmir Mota de Oliveira - Cajati - Cascavel-PR. Em seu percurso textual discute a organização do movimento dos trabalhadores rurais sem terra e protagonismo (in)visível das mulheres na luta pelo acesso ao direito à terra, permanência e organização produtiva coletiva. Conhecimento resultante de revisão bibliográfica e de pesquisa empírica, cujo objetivo primário foi apontar a participação do MST e da mulher na efetivação da reforma agrária no Brasil. Dentre os resultados aproximativos da discussão, é possível destacar que a questão agrária se faz presente na história política, geográfica, territorial, cultural e da equidade de gênero no país, marcada por contradições, violações e conflitos nas lutas por direitos fundamentais, igualitários e com justiça distributiva. Nesse contexto de valores e princípios de direitos humanos, de condições reais de seguridade vital, reiteramos a particularidade da participação histórica e política das mulheres no desenvolvimento rural sustentável.
\end{abstract}

Palavras-chave: Direito à terra. Reforma agrária. Sustentabilidade. Protagonismo das mulheres.

\begin{abstract}
:
This article integrates the dissertation research The Woman in the Family Productive Process with Sustainability in the Settlement Valmir M ota de Oliveira - Cajati - Cascavel-PR. In its course discusses the organization of the landless workers' movement and women' (in) visible protagonism in the struggle for access to land rights, permanence and collective productive organization. Knowledge resultant of literature review and empirical research, in which the main goal was to point out the participation of the LWM and the women in the achievement of the land reform in Brazil. Among the topics of discussion, it is possible to highlight that the agrarian question is in within political, geographical, cultural history and gender equality in the country, marked by contradictions, violations and conflicts in egalitarian fundamental rights and distributive justice. In this context of values and principles of human rights, of real conditions of vital security, we reiterate the particularity of the historical and political participation of women in sustainable rural development.
\end{abstract}

Key-words: Right to land. Land reform. Sustainability. Women protagonism.

\footnotetext{
* Assistente Social pela UNIOESTE. Pesquisadora do Grupo de Estudo e Pesquisa em Políticas Ambientais e Sustentabilidade - GEPPAS - UNIOESTE e do Grupo Interdisciplinar e Interinstitucional de Pesquisa e Extensão em Desenvolvimento Sustentável (UNIOESTE). Mestre e Doutoranda em Desenvolvimento Rural Sustentável DRS, pela UNIOESTE, Campus de Marechal Cândido Rondon.

** Professora Associada do Curso de Serviço Social e dos Programas de Mestrado em DRS, Serviço Social e de Ciências Ambientais da UNIOESTE. Pós-Doutora em Meio Ambiente e Desenvolvimento pela UFPR. Pesquisadora Líder do Grupo de Estudo e Pesquisa em Políticas Ambientais e Sustentabilidade - GEPPAS.
} 


\title{
Introdução
}

\begin{abstract}
Para estudar o passado de um povo, de uma instituição, de uma classe, não basta aceitar ao pé da letra tudo quanto nos deixou a simples tradição escrita. É preciso fazer falar a multidão imensa dos figurantes mudos que enchem o panorama da História e são muitas vezes mais interessantes e mais importantes do que os outros, os que apenas escrevem a História.
\end{abstract}

(Sérgio Buarque de Holanda)

No Brasil, a terra foi inicialmente explorada por índios que aqui viviam e dela usufruíam dos recursos naturais para suprir necessidades de subsistência, produtivas e de seguridade de vida. Quando foi iniciado o processo de apropriação do Brasil, em 1500, as terras brasileiras foram consideradas Colônia Portuguesa e pertencentes ao rei de Portugal, que se julgava dono delas, menosprezando ou ignorando a presença dos índios nativos em relação à posse da terra.

Assim sendo, passou a doá-las em forma de sesmarias a quem comprovasse ter condições de explorá-las, conservando, contudo, o domínio da propriedade para a Coroa, ou seja, a quem fosse concedida a posse, Ihe seria permitida apenas a exploração da terra (DELGADO, 2012).

As terras, cuja posse era concedida, eram aquelas consideradas de trabalho, normalmente as que ficavam à margem da grande lavoura escravista (grandes extensões exploradas por pessoas que tinham como trabalhadores escravos), sendo então pequenas extensões de terras cuja posse se efetivava por meio de parceiros, ou posseiros e que se utilizavam da agricultura de subsistência (DELGADO, 2012). De acordo com Delgado (2012, p. 8) contudo, na raiz histórica de nosso país está a apropriação ilegal de terras, ato legalizado pelos delegados da terra da época.

Nessa aproximação introdutória sobre a apropriação das terras em defesa de direitos e necessidades vitais de subsistência e de posses marcadas por desigualdades sociais inerentes à formação da sociedade brasileira, que historicamente se caracterizou por um processo de concentração de renda e poder em nível exponencialmente maior do que em outras sociedades, discorremos sobre o pensamento de Sérgio Buarque de Holanda e 0 Brasil (CANDIDO, 1998).

Para o grande historiador e crítico literário, deveríamos empenhar esforços em desvendar, no passado, forças de transformação que pudessem indicar caminhos para a liberdade, ruptura de traços e valores arcaicos, herdados da colonização portuguesa e do 
Império, com vistas ao alcance da mudança social. Implicando, necessariamente, como discorrido no livro Raízes do Brasil, uma transformação profunda e estrutural das relações entre o rural e o urbano no Brasil de seu tempo.

Para Dias (1998), Sergio Buarque de Holanda, em sua obra Raízes do Brasil, fazia uma crítica à reformas, que, em vez de proporem e desencadearem mudanças, reforçavam ainda mais as tradições às quais a autora Dias (1998, p. 13) destaca com uma citação de Holanda (1979, p. 121): “Aqueles que pugnaram por uma vida nova representavam, talvez ainda mais do que seus antecessores, a ideia de que o país não pode crescer pelas suas próprias forças naturais: deve formar-se de fora para dentro, deve merecer a aprovação dos outros", reforçando, dessa forma, a lógica de dominação e exploração do chamado velho mundo utilizando-se dos mesmos modelos sociocultural e econômico aqui no Brasil, expropriando-se as riquezas locais, gerando e mantendo os latifúndios.

Dessa maneira, grande parte do povo brasileiro teve o acesso à terra negado. Ficando sem atividade no meio rural, acabou migrando para os centros urbanos ou tornouse bóia-fria. Aqueles que continuaram no campo foram tratados como posseiros e considerados marginais pela agora condição de ilegalidade do direito ao título de propriedade (SILVA, 2004) gerada pela promulgação da Lei das Terras, cuja finalidade principal, ainda de acordo com Silva (2004, p. 40), era o de evitar que "os imigrantes e os trabalhadores brancos pobres, negros libertos e mestiços tivessem acesso à terra", facilitando a mão de obra para os latifundiários.

Esse impedimento do pequeno produtor, mestiços e imigrantes à terra mostra como constituiu-se o latifúndio no País. Apenas em 1822, foi suspensa a concessão de sesmaria e o direito dos posseiros foi reconhecido. Caso as terras estivessem efetivamente cultivadas, "os posseiros" teriam direito a elas, independentemente da extensão em uso.

Para Delgado (2012), a Lei de Terras trouxe em seu bojo, ainda que indiretamente, o berço da "grilagem de terras", pois quando instituiu o domínio público, houve terras devolutas que passaram a ser alvo de posse, ou seja, griladas. Por mais de 300 anos 0 modelo colonizador imposto pelas capitanias hereditárias criou o sistema de latifúndios e permitiu, ao mesmo tempo, a manutenção do sistema escravista. 0 capitalismo vigente no meio rural brasileiro sempre reagiu com violência extrema a to das as tentativas de mudança no sistema. 
Por fim, o golpe de 1964, período em que integrantes da mobilização pela reforma agrária foram perseguidos, enterrou de uma vez por todas a esperança dos trabalhadores rurais em relação às reformas pretendidas por eles e demais categorias de base. Restou, assim, apenas exílio, tortura e morte para os principais líderes do movimento de reforma agrária, que pretende realizar, além de uma redistribuição de terras, a diminuição da miséria, uma maior oferta de alimentos, a ampliação da discussão no sentido de reformar as leis e as práticas fundiárias e acabar com o modelo arcaico do distributivismo como forma de ocupação agrária.

A reforma agrária está amparada pela Carta Magna brasileira e embora o MST perturbe a ordem dominante por evidenciar os conflitos fundamentados no acesso desigual à terra e à diversidade de modos produtivos, está em busca da garantia de direito e de cidadania. Por meio da reforma agrária regulariza e fortalece a produção familiar uma vez que a propriedade é considerada pequena propriedade, destinada à produção ou agricultura familiar. Contudo, segundo Fernandes (1999, p. 39), o progredir da luta pela terra fez com que a reforma agrária construísse uma nova faceta, passando a ser entendida como uma questão da justiça, "além de ser uma questão econômica, social, etc.".

Para Deere (2004, p. 177), “[...] a reforma agrária estava uma vez mais na pauta nacional brasileira da década de 1980, em grande parte como resultado das ações do M ST [...]", apoiado pelos sindicatos rurais, que tiveram um papel importante nesse processo de luta, chegando a sua previsão à Constituição Federal de 1988.

Fernandes (2004, p. 2) acredita que, “[...] a questão agrária sempre esteve relacionada a conflitos por terra [...]". Para o autor, esses conflitos vão além do momento de enfrentamento entre as classes e o Estado. Ainda para o autor, "[...]. No caso da luta pela terra, é o modo de enfrentamento à forma capitalista de acumulação do capital e destruição da relação social do capital que se reestrutura ou se reterritorializa a relação social familiar camponesa" (FERNANDES, 2004, p. 7), uma vez que o modelo de produção agrícola moderno adotado pelo Brasil está alicerçado na concentração da propriedade privada e do uso do solo, impactando de modo conflitante no modelo produtivo da agricultura familiar.

$\mathrm{Na}$ luta pela efetivação da reforma agrária e para que essa se constitua em mecanismo de distribuição justa da propriedade ou da terra e, portanto, fator que promova justiça social, há como principal ator o movimento dos Trabalhadores Rurais Sem Terra - 
MST e também o Movimentos das Mulheres do Campo, que lutam pelo direito à propriedade e direitos relacionados ao gênero feminino, participando efetiva e diretamente na luta pela reforma agrária e pela posse da propriedade.

\section{0 protagonismo das mulheres trabalhadoras rurais: espaço de construção de classe e identidades}

A Mulher é um ser social e, como tal, está no contexto da sociedade, logo, perpassa e transita em suas esferas, contudo, durante séculos, ficou subordinada aos valores socioculturais de submissão ao patriarcado. Assim, era apenas "apêndice" do homem fosse na condição de pai, esposo, irmão, etc.. Entretanto, à medida que a sociedade e os meios de produção capitalista foram se desenvolvendo, a mulher foi ingressando no mercado na esfera cultural, econômica e do trabalho, libertando-se, com isso, de amarras sociofamiliares, mesmo que de forma tímida e lenta, assumindo seu papel de sujeito, cidadão e de produção, portanto, capaz de conhecer, desenvolver, administrar, dentre outras capacidades.

Essas mudanças e a crise, de acordo com Leff (2014, p. 17), "[...] lleva al mundo a despojarse de lasrepresentaciones de la sociedade que había construído[...]", levando-se ao repensar da posição de cada um em relação a si (seu papel), ao ambiente e à sociedade. Foi com esse movimento que as mulheres agricultoras e sem terra conseguiram transcender a esfera do lar, do trabalho sem valorização para uma categoria de luta na esfera dos direitos e por direitos. Entende-se como pessoa de direito, uma classe social ${ }^{1}$, a classe dos trabalhadores, e, nesse contexto, de trabalhadoras rurais, com direito à terra e respeito por essa condição de classe.

Quando se transcende para essas esferas, criam-se novas representações em relação à vida tanto como sujeito individual como coletivamente e também nas áreas de conhecimento, levando-se ao repensar da posição de cada um em relação a si (seu papel), ao ambiente e à sociedade.

\footnotetext{
${ }^{1}$ Para Marx, classes sociais são proletários e burgueses que se constituem e se afirmam nas relações econômicas estabelecidas entre detentor dos meios de produção e detentor de força de trabalho a ser vendida em forma de trabalho/produção. De acordo com Simionatto (2011), para Gramsci, a constituição de classe se dá além da esfera econômica, transcendendo para a esfera da política, da cultura, educação, da história individual e coletiva.
} 
Para tanto, as mulheres empreenderam a luta pelo seu reconhecimento como trabalhadoras e, portanto, detentoras do direito à aposentadoria e também o acesso à terra com condições dignas de vida a si e a sua família (MONTAÑO; DURIGUETTO, 2010). Cabe destacar que as mulheres, ao iniciarem a luta pela terra, se colocaram diante da luta de classes e do enfrentamento da questão de gênero (SCHWENDLER, 2009). Diante disso e da criação do Movimento das Trabalhadoras Rurais, o Movimento de Mulheres Camponesas (MMC), que é um dos quatro movimentos componentes da via campesina, articula e fortalece a luta pelos direitos da mulher e da reforma agrária.

Segundo Paulilo (2009, p. 179) o movimento das mulheres agricultoras, fortalecido por outros movimentos sociais "ligados ao campo", consegue dar visibilidade à questão da igualdade de gênero no espaço rural. Chama-se atenção ao fato de, mesmo havendo mudanças nas relações de gênero no meio rural, ainda "[...] permanecem relações desiguais de poder que se expressam no campo afetivo, econômico e político" (BRASIL, 2004, p. 17).

Quanto ao espaço rural ou da complexidade da luta pela terra, esta envolve a participação da mulher no processo de luta por uma reforma agrária efetiva, o que implica a garantia da agricultura familiar com sustentabilidade em que a mulher seja, também, agente decisório e propulsor das atividades agrícolas, bem como da comercialização da produção do lote.

Contudo, as conquistas e a participação das mulheres na sociedade e nas decisões sociofamiliares e políticas, como dito anteriormente, foi um processo lento, de muita luta e pequenas conquistas ao longo da história, para que hoje pudessem estar em um processo ativo de participação. Embora discriminada e relegada em alguns espaços, a mulher está se empoderando de cidadania e autonomia.

A ocupação, de acordo com Fernandes (2004, p. 8), "gera o conflito", sendo necessário se atentar à conflitualidade e suas dimensões. Assim, todo processo de ocupação e desapropriação, mesmo sem confronto direto, tem em seu bojo a conflitualidade, isto é, pairam, em seu decorrer e seu interior, relações de conflitos e de poder. Contudo, Fernandes (2004) destaca que embora o campesinato lute contra a ordem dominante, ele não chega a romper e superar à subalternidade.

Relacionada à luta das mulheres, é visível a busca pelo espaço participativo, pela autonomia e pelo reconhecimento. Para Demo (1996), essa luta é capaz de contemplar o 
desejo e empenho das mulheres na sociedade brasileira para essa conquista via a participação nas diferentes esferas da sociedade e das famílias.

No processo de participação da mulher na ocupação da área do Assentamento Valmir Mota de Oliveira, que é a pesquisa, sempre houve uma preocupação em fomentar e instigar a participação da mulher dentro do movimento do MST de um modo geral, por meio de discussões e do delineamento de estratégias para sua efetivação.

\section{A ocupação da terra, permanência e processo produtivo familiar: a luta das mulheres no Assentamento Valmir Mota de Oliveira - Cajati - Cascavel-PR}

Para compreendermos o objeto de estudo em questão, cabe delinearmos brevemente a metodologia da pesquisa para, posteriormente, apresentarmos os resultados. Assim, a pesquisa ocorreu no ano de 2015, junto ao Assentamento Valmir M ota de Oliveira, localizado no distrito de São João, município de Cascavel - Paraná. A construção do trabalho de pesquisa deu-se dentro de uma abordagem de pesquisa qualiquantitativa, devido ao fato de as pessoas envolvidas no processo serem consideradas sujeitos que elaboram conhecimento em suas ações cotidianas, no contexto em que estão inseridas. Além disso, esse tipo de abordagem permitiu entender esse sujeito sem desvinculá-lo do contexto em que vive e age, de acordo com sua perspectiva de ver, pensar e compreender esse meio, bem como quantificá-lo.

Como metodologia de coleta de dados foi utilizado um questionário, com questões abertas e fechadas no intuito de compreender o perfil socioeconômico dos entrevistados, e a entrevista semiestruturada. Quanto aos cuidados éticos, submeteu-se a pesquisa ao Comitê de Ética em pesquisa, obtendo-se aprovação ${ }^{2}$. A partir disso, foram elaborados termos de consentimento livre e esclarecido, que foram assinados pelos sujeitos pesquisados. Os sujeitos elencados foram escolhidos juntamente com a coordenação do assentamento, embora a proposição inicial tivesse sido fazer sorteio dentre todos os moradores.

Em razão de no assentamento haver distribuição por grupos de famílias, optou-se então por elencar um número representativo e proporcional ao número de famílias que compunham cada grupo. As famílias foram escolhidas aleatoriamente dentro desses grupos,

\footnotetext{
${ }^{2}$ Parecer $n^{0}$. 1.179.491. de 30/07/2015.
} 
respeitando-se, e tendo como base, a organização destes dentro do assentamento. De cada grupo, foram elencadas 04 mulheres como representantes desse grupo, totalizando 32. Porém, como três grupos são formados por 11 famílias, em um deles, foram elencadas 05 mulheres, fechando, dessa forma, as 33 entrevistas propostas e que totalizavam os $40 \%$ da amostra elencada no universo da pesquisa.

Essas entrevistas foram realizadas com mulheres dos domicílios, as quais participaram como representantes das demais, residentes e atuantes no assentamento. Cabe ressaltar que uma entrevista foi realizada com uma das coordenadoras, também baseada em um roteiro, buscando conhecer 0 processo de ocupação da área e 0 assentamento das famílias nos lotes do Assentamento Valmir M ota de Oliveira, totalizando, assim, 34 entrevistas realizadas. 0 tratamento dos dados foi realizado quantitativa e qualitativamente, utilizando-se da técnica de análise de conteúdo.

Segundo 0 que a pesquisa mostrou, as famílias vieram e ficaram próximo à BR 277 por cerca de dois anos, para que então pudessem se instalar definitivamente em suas terras. Nessa espécie de acampamento, organizaram suas casas, ou mesmo barracos, e iniciaram o plantio de frutas e verduras (PASTÓRIO, 2015).

O Assentamento Valmir Mota de Oliveira resultou da ocupação de uma área da fazenda Cajati, que pertencia à empresa IMAPAR - Cajati Reflorestamentos e Agricultura Ltda. e vinha com acampamentos do MST ali instalados já há alguns anos, situada no Distrito de São João do Oeste, município de Cascavel, Paraná. Foi regularizado em 2010, após “[...] 13 anos de ocupação da área [...]" (CARIGNANO, 2012, p. 1). Após aquisição da propriedade pelo INCRA, em 2010, foi realizado o processo de desapropriação, mas somente em 2013 as famílias foram selecionadas.

Segundo os relatos da Coordenação local, dados obtidos durante a pesquisa, esse assentamento tem uma característica diferente, pois foi uma conquista do movimento estadual e do MST. As famílias assentadas vieram de vários locais por se entender que essa era uma conquista do movimento e não de um acampamento específico. A liderança do acampamento solicitou ao INCRA que considerasse "[...] famílias de todos os acampamentos no entorno [...]" e também pessoas que estivessem incluídas no Plano Nacional da Reforma Agrária, bem como aptas a receberem o lote (PASTÓRIO, 2015, p. 94). No Assentamento 
Valmir Mota de Oliveira, há 83 famílias, [...]"desta forma, o assentamento "se caracteriza então pela junção, além da agroecologia [...]" (PASTÓRIO, 2015, p. 94).

Um dos critérios estabelecidos pela liderança foi 0 de que se levasse em consideração a participação dos integrantes nas discussões e que tivessem "[...] aptidão para estar na roça, para a agricultura, para a agroecologia" (PASTÓRIO, 2015, p. 94).

Assim, as famílias que compõem o Assentamento Valmir Mota de Oliveira são oriundas dos acampamentos: Primeiro de Agosto, Dorselina Folador, Sete de Setembro, sendo este último, de acordo com os dados coletados, "[...] uma área que nós ainda temos ocupada hoje [...]" junto ao complexo da fazenda Cajati. Vieram, também, famílias da fazenda Rimafra, Casa Nova, Olga Benária, Antônio Tavares, Casa Amarela Termas, Paranapanema, de um acampamento do Município de lbema e 10 famílias da brigada José Martins, resultando na composição do assentamento. A composição deste também pode ser considerada um processo de construção no coletivo dos acampamentos do entorno do complexo Cajati e região e do MST do estado.

Dessa forma, famílias de todo o estado foram contempladas, totalizando 83 famílias, das quais duas acabaram saindo e, por isso, novas famílias foram selecionadas pelo INCRA para ocuparam tais terras, não ocorrendo então venda das áreas.

Quanto à presença e participação da mulher nos movimentos sociais voltados à conquista da terra e aos direitos sociais e da mulher, a coordenadora do Assentamento Valmir M ota de Oliveira afirmou: "[... ] nós sempre discutimos na brigada em nível de estado, mesmo no movimento, a importância da família estar nesse espaço para o acampamento [...]" (PASTÓRIO, 2015, p. 99). Tem-se, dessa forma, a família como o ponto fundamental nas relações e na vivência do coletivo, com papel importante nas conquistas realizadas, assim como a importância da mulher, que está inserida no contexto familiar e na luta dentro do MST.

Para tanto, internamente no assentamento, buscaram-se mecanismos de participação e organização, baseados em uma estrutura em que as tarefas fossem distribuídas e divididas de forma igualitária entre homens e mulheres. Nessa organização, de acordo com a coordenadora, constituíram-se 08 núcleos de famílias, contando com 10 a 11 famílias em cada um, cuja coordenação e direção são exercidas por um homem e uma mulher, no intuito de fortalecer e desenvolver a participação da mulher no processo decisório. 
Quanto a participação da mulher nas atividades no assentamento, a coordenadora destaca que, em relação à produção e nos lotes, a mulher tem uma participação ativa. Ela ressalta que, atualmente: "[...] a gente percebe uma participação muito grande da mulher na discussão do lote, se ela consegue ter uma voz mais ativa, tem uma diversidade [...]", (PASTÓRIO, 2015, p. 103), ou seja, pode-se dizer que há sustentabilidade, pois as mulheres produzem uma variedade maior, podem manter o sustento da família e comercializar 0 restante da produção, transformando o excedente em renda para a aquisição de outros produtos que não podem ser ali produzidos.

Em relação à participação em movimentos voltados à luta das mulheres junto à amostragem pesquisada, pode-se constatar que algumas têm participação apenas em organizações locais, sendo que os motivos da não participação em movimentos fora do assentamento ou mesmo nas reuniões dentro do assentamento são variados, mas normalmente voltadas ao trabalho, como fica evidente na fala de E17: "[...]. Eu participei bastante quando estava acampada, né, mas agora tá difícil, muito trabalho, a gente trabalha bastante, como eu trabalho sozinha na agricultura [...], não tem como participar [...]." (PASTÓRIO, 2015, p. 104).

Contudo, há várias entrevistadas que mantêm a participação em movimentos, capacitações, mobilizações em nível estadual e nacional, como E9, E12, E15, E29, E32, as quais ainda participam de movimentos como o M MC, M AB, Levante Popular da Juventude e $P J R$, deixando clara a participação constante antes do assentamento e agora, após assentadas, diferindo de outras entrevistadas.

E9Ah! Além do MST? Tenho o MMC que são, [...] no cotidiano, por exemplo, da minha turma, nós temos muito forte também a relação do $M A B$ e do Levante Popular da Juventude que pega vários jovens inclusive do M ST que faz parte, né.

E12 Assim é, geralmente quando a gente faz algumas tarefas junto porque quando a gente vai fazer, a gente sempre tem os parceiros dos outros movimentos da terra né, [...] , então tem vários outros movimentos que juntam mulheres que a gente não tá lá diretamente, mais né a gente tá sempre em contato com muitas, muita formação ali junto.

E15 Eu sempre participo desde que entrei no movimento venho participando das atividades gerais do movimento das mulheres. Desde a organização do dia 08 de março, [...], sempre que tem alguma atividade a gente tá junto, no assentamento também na perspectiva de organização e planejamento [...].

E29 Participo da jornada estadual, da jornada de agroecologia, encontro ampliado, encontro de mulheres, vai além daqui do assentamento.

E32 Eu continuo nas atividades dos encontros, mobilização. Continuo ativamente, até porque eu estou na escola, a gente também tenta envolver as pessoas da escola. A gente continua participando (PASTÓRIO, 2015, p. 104-105). 
Quanto a participação do processo de organização do lote, plantio, cultivo e da comercialização, a maioria das mulheres entrevistadas participa ativamente desse processo, com exceção de algumas que trabalham fora e que ajudam no processo de decisão - embora os esposos estejam mais à frente do processo total de cultura. Faz-se exceção à entrevistadas E7: "[...] Era meu marido, agora, que ele morreu tem quarenta dias, né, agora tem que ser eu mesmo."; E15: "É só eu e as crianças, então decido tudo", sendo esta uma das famílias chefiadas por mulher no assentamento; e E12: "Como sou só eu e minha filha, nós decidimos, às vezes, conto com amigos para ajudar dar ideias como para o jardim [...]" (PASTÓRIO, 2015, p. 105).

A entrevistada E30 disse: "[...] Eu trabalho fora e ele fica no lote. Quando um trabalha, o outro cuida do lote.". Fica claro, assim, que, mesmo com a propriedade do lote, ainda se faz necessário o trabalho fora, o que indica a presença dos velhos padrões sociais, de acordo com os quais a mulher vende sua mão de obra para ajudar na renda e se manter na propriedade com uma melhor qualidade de vida (PASTÓRIO, 2015, p. 106).

A entrevistada E27 destaca que, na propriedade, quem decide e toma a frente é ela, relatando que, a partir do momento em que começou a fazê-lo, começaram a avançar na produção: “[...], depois que eu tomei conta começou ir pra frente"(PASTÓRIO, 2015, p. 106).

Contudo, algumas entrevistadas deixaram claro que é mais o esposo quem faz, mas elas também opinam. Utilizou-se como referência a fala de $\mathbf{E} \mathbf{1}$ que destaca: “[...],mas a gente opina junto, mas é ele que toma a frente." (PASTÓRIO, 2015, p. 106).

A entrevistada E4 destacou que, por questões de saúde, quem está mais à frente do trabalho no lote é o esposo, mas que a decisão de como organizar, o que plantar é conjunta: "A gente discute e faz conjunto, a decisão é junto como é só eu e ele, e eu pouco valho, [...] daí só ficava pra ele o plantar, cuidar, colher." A E2 relatou: [...] eu ajudo plantar, colher, opino, dou opinião de como planta, a hora de plantar". A E9 expôs: "bom é nós mesmo que trabalhamos né, é meu marido e eu na medida do possível ajudo. Eles [os filhos] têm também o estudo e as demandas do dia a dia, se bem que eles também ajudam aqui dentro e o que eu posso, eu faço lá fora [...]" (PASTÓRIO, 2015, p. 106).

A entrevistada E16 destacou que, até recentemente, ela tomava a frente de tudo, inclusive a posse do lote está apenas no nome dela, pois quando saiu o documento, ela estava sozinha: "Sim. Até quatro meses era só eu sim, agora dá para dividir." Desse modo, o 
fato de não ter um companheiro leva essas mulheres a tomarem as decisões em relação a toda a condução da vida familiar e da propriedade, obrigando-as, de certa forma, a assumirem o gerenciamento da vida socioprodutiva da família (PASTÓRIO, 2015, p. 106).

A entrevistada $\mathbf{E 7}$ diz que era tudo o esposo que fazia, mas, agora que está viúva, ela terá de tomar as decisões com os filhos, precisará se inteirar do funcionamento de questões bancárias, de venda, de compra, dentre outras. Todavia, ela tem os filhos, com quem pode contar e que acompanhavam as atividades desenvolvidas pelo pai. A entrevistada E31 diz ser "Basicamente eu, se discute tudo coletivo, mas no lote como eu fico mais direto é tudo eu [...]" (PASTÓRIO, 2015, p. 106).

Brumer e Anjos (2008) descrevem que, com base em pesquisas realizadas em 2005 por um grupo interministerial, as mulheres ainda têm uma autonomia reduzida em relação ao gerenciamento da renda provinda de seu trabalho ou de créditos que possam acessar pelo fato de não dominarem o processo de comercialização e gerenciamento da propriedade. Isso dificulta a autonomia, o empoderamento econômico e o poder de decisão das mulheres.

As falas das entrevistadas apresentadas até o momento demonstram que as mulheres no assentamento, com base na história de luta e militância, conseguiram, de certa forma, sair da esfera da casa e da reprodução para a esfera de produção. Medeiros (2008, p. 15) destaca que "A família assentada reorganiza-se, mas as posições tradicionalmente atribuídas se reproduzem", o que deixa um sinal de alerta na análise das relações estabelecidas no que se refere ao gênero e à participação real da mulher nas decisões.

Outra questão em que fica evidente a participação da mulher é na aplicação do recurso do primeiro apoio recebido via INCRA. A primeira parcela do recurso, recebido em 2015 , veio em nome das mulheres, que são as titulares principais ou as primeiras titulares da propriedade. Quando questionadas sobre tal, obteve-se resposta unânime de que as mulheres ajudaram na decisão sobre o que ou como aplicar esse recurso. Para representar 0 conteúdo expresso na unanimidade das respostas obtidas, elencou-se a fala das entrevistadas E25 e E28:"[...] sim, decidimos juntos [...]"(PASTÓRIO, 2015, p. 107).

Assim, pode-se constatar que houve uma participação ativa das mulheres na decisão de aplicação do recurso recebido do primeiro apoio, com exceção da entrevistada E27 que disse: "Ah! Eu fui investindo, arrumando a casa, comprando as coisas para dentro 
de casa, investindo na terra. Não sobrou nada para investir lá fora, comprei muitas coisas aqui para casa mesmo, investi na casa”. Ela relatou ainda: "[...] eu que tive que tomar as providências [...]", (PASTÓRIO, 2015, p. 107) demonstrando um papel mais ativo nas decisões em relação à aplicação do recurso e também na organização do lote, definindo como, o que e quando plantar, obtendo melhores resultados a partir de então.

Nesse sentido, a entrevistada E26 declarou não ter recebido esse apoio e uma das coordenadoras do assentamento disse que até 0 momento há oito famílias do Assentamento Valmir Mota que ainda não receberam nenhum recurso, pois há algumas questões burocráticas e documentais para resolver. Isso dificulta a produção e organização do lote e interfere diretamente na venda de mão de obra, podendo interferir, também, na permanência da família na propriedade (PASTÓRIO, 2015).

Quanto a esse recurso, a entrevistada E29 disse: “[...] nós ainda não gastamos esse recurso porque estamos esperando para comprar uma lona específica para captar água da chuva.", logo, já está decidida a aplicação. Essa foi a prioridade definida para o investimento do recurso pelo casal. Quando ela se refere à nós, é possível perceber que a participação e a decisão conjunta fazem parte da rotina familiar (PASTÓRIO, 2015, p. 108).

Quanto à forma de aplicação do recurso, varia muito de uma família para outra. Algumas investiram parte do recurso em alimentos, como o caso da entrevistada E15: “[...] eu gastei a metade com alimentação [...]". E31 também destacou ter utilizado parte do recurso para alimentos: "[...] uma parte a gente utilizou para comprar alimentação [...]". Outras aplicaram em melhoria ou finalização da habitação, como é o caso de E5: “[...] compramos o piso da casa e fizemos o lado de fora." Algumas investiram na propriedade, como E24: “[...] comprei aqueles palanque, comprei dois rolo de arame, assim mesmo foi parte do dinheiro de nossa aposentadoria, ainda assim não deu [... ]"; e outros em pastagem ou equipamentos necessários para um melhor manejo nas atividades na propriedade (PASTÓRIO, 2015, p. 108).

Dessa forma, pôde-se visualizar que essa condição rompe, de certo modo, com a autoridade da figura masculina como chefe de família. A mulher está saindo da condição histórica de exclusão na esfera comercial, como em bancos e cooperativas. Um fator que ajudou muito nisso foi o fato de a mulher ter a titularidade da posse da propriedade e ter, por exemplo, recursos, como o primeiro apoio, no nome dela. Devido a isso, elas são obrigadas a se inteirarem desse mundo comercial antes atribuído aos homens, gerando 
assim, o empoderamento das mulheres no que diz respeito a opinar e ajudar na decisão, aplicação e a organização dos lotes, bem como na divisão das tarefas.

Outra questão que chama a atenção e que se investigou junto aos sujeitos da pesquisa foi a titularidade em relação à posse da propriedade, haja vista que a titularidade da terra em nome do homem sempre representou o poder desse em relação a mulher nas decisões relativas à produção e comercialização, isto é, na estrutura patriarcal, produziu uma forma de dominação em relação a mulher, restringindo sua participação no cotidiano de decisões, inclusive, na forma de educar os filhos, nas atividades de renda.

A titularidade da posse da propriedade representa hoje uma conquista da mulher e permite a ela possibilidades de autonomia, empoderamento político e sociofamiliar e, acima de tudo, significa poder permanecer na terra em situações de falecimento do esposo/companheiro. Como destaca Medeiros (2008, p. 16), "[...] a titulação da terra permite à mulher o direito de permanecer na propriedade em caso de viuvez ou separação, trazendo, dessa forma, uma estabilidade à família, sendo assim um fator de extrema importância [...]".

A titularidade da terra e a posse do lote somente foram possíveis por meio da participação da mulher na luta pelo acesso à terra e condições de dignidade para a família (SOUZA, 2008). Contudo, essa não é prerrogativa especificamente da mulher no caso de Assentamentos de Reforma Agrária, a não ser em casos de a mulher ser a chefe da família, pois, de outro modo, a titularidade é compartilhada, sendo a mulher a titular um e o homem titular dois, como já mencionado.

Essa prática, adotada pelo INCRA, deixa evidente um avanço na questão da cidadania feminina, assim como o fato de terem os créditos disponíveis em seu nome. Exemplo disso, segundo a coordenadora, é o valor do primeiro apoio, cerca de $R \$ 2.400,00$, que as famílias receberam e que veio para recebimento pela mulher.

O cartão para acessar esse recurso veio em nome da mulher, contudo, a coordenadora destaca que isso levou a conflitos em algumas famílias "[...] em função de que, no campo, temos muito essa questão galgada na família patriarcal, na figura masculina.". Porém, isso é algo que, culturalmente, pode ser mudado por meio de trabalhos voltados à importância do papel feminino na família e no processo produtivo. Ademais, esta 
é uma mudança já iniciada uma vez que as mulheres estão tendo acesso aos recursos, o que, até então, era realizado apenas pelo homem, chefe da família.

Entretanto, 0 acesso à titularidade principal no documento da propriedade e aos recursos as torna mais autônomas, mas gera ainda situações conflituosas. Apesar disso, com o tempo, pode se tornar um fator preponderante para o empoderamento político, social, familiar e econômico das mulheres no meio rural, bem como pode representar a segurança, a posse da propriedade, da moradia e a manutenção da família unida e em condições de sobrevivência digna.

Ressalta-se nesse contexto que quatro dessas famílias são chefiadas por mulheres. Na luta pela conquista da terra via reforma agrária, segundo M edeiros (2008, p. 11), muitas vezes, não se faz referência às mulheres, que são atoras nas lutas empreitadas pelo movimento e que, frequentemente, ficam esquecidas, reduzidas à 'massa', a menos que consigam se destacar como líderes dentro do movimento.

A titularidade da mulher na propriedade do lote também foi investigada junto às entrevistadas no sentido de aferir se essa questão havia gerado conflitos entre os casais. As entrevistadas destacaram, na grande maioria, que não houve conflitos. Constata-se isso em algumas respostas como a da entrevistada E30: "Eu sou a titular, para nós foi normal, porque os direitos são iguais, não tem nada a ver se está no nome de um ou de outro porque nós ganhamos o lote juntos, ficamos o tempo todo acampados juntos." Nessa fala, percebe-se uma naturalização da condição da mulher constar como titular principal no documento de posse da propriedade. Contudo, algumas entrevistadas disseram haver alguns companheiros que ficaram ressentidos, como fica evidente na fala de E24: "Alguns ficou, mas fazer 0 que, tem que respeitar porque a mulher também tem valor [...]" (PASTÓRIO, 2015, p. 111).

Segundo Barreto (2004), a ira masculina se manifesta e ganha força quando o poder é perdido ou fica ameaçado. Esse pode ser perdido pelo homem tanto pelas ações quanto pelas conquistas das mulheres em termos de direitos, como a igualdade e autonomia econômica, ou qualquer forma de empoderamento da mulher. Esse sentimento pode se manifestar em forma de violência física, sexual e/ ou psicológica, o que, em situações como a titularidade, pode culminar em resistência por parte do homem em dividir a responsabilidade no que se relaciona às decisões sobre a organização do lote $\mathrm{e}$ comercialização dos produtos. 
Hoje, as famílias do Assentamento Valmir Mota de Oliveira, segundo dados coletados durante a pesquisa junto às entrevistadas, têm a preocupação com questões de habitação e crédito rural, uma vez que, até o momento, as famílias desse assentamento receberam apenas $\mathrm{R} \$ 2.400,00$ de apoio inicial, um valor considerado relativamente pequeno, destinado, segundo a coordenadora entrevistada, a "[...] viabilizar a nossa produção, esse apoio inicial é antes do Pronaf, veio para a gente comprar ferramentas, comida, esse processo não é fácil." (PASTÓRIO, 2015, p. 120).

Quanto ao tempo de moradia no lote destinado à família, varia entre um mês a três anos, cabendo destacar que uma das famílias ainda não conseguiu instalar energia elétrica e água em sua propriedade, nem construir a casa, pois não obtém recursos suficientes com 0 trabalho do esposo e, como ela tem crianças pequenas, não consegue trabalhar fora, ficando com os afazeres domésticos e cuidado dos filhos.

A família destaca que o primeiro apoio veio, mas não foi suficiente para sanar as necessidades de estrutura e viabilizar a mudança, mas que, na medida do possível, estão organizando essa estrutura e plantio. Ela já sabe como destinar/organizar a produção, mas precisa esperar um pouco mais para efetivar esse desejo, o que demonstra a necessidade de revisão das ações e políticas de apoio e acesso aos recursos destinados para beneficiários de projetos de reforma agrária, principalmente, no tempo de acesso aos recursos para a família se instalar com dignidade na propriedade, que foi conquistada após anos de permanência em acampamentos.

A questão volta-se, dessa forma, não apenas ao acesso, mas à permanência na terra/propriedade, tornando a reforma agrária mais efetiva. A luta pela reforma agrária contou e conta com o protagonismo das mulheres no sentido do direito à terra e no direito de ser vista como trabalhadora rural. Esse direito possibilita à mulher a inclusão nas relações de produção em termos de igualdade e, de certo modo, nas relações econômicas, com uma autonomia maior em decidir questões relacionadas ao cotidiano doméstico.

\section{Considerações Finais}

A Reforma Agrária foi o movimento propulsor para que muitas famílias passassem a ter uma propriedade para sua sobrevivência por meio da agricultura familiar. Contudo, se trata de um processo lento provocado pela pressão constante do Movimento dos 
Trabalhadores Rurais Sem Terra. Essa realidade demonstra que a reforma agrária, em sentido pleno, ainda está longe de ocorrer no Brasil, uma vez que, para isso, é necessário haver uma mudança estrutural no país e nas políticas para a Reforma Agrária.

Quanto a participação da mulher na luta pelos seus direitos, se faz presente na sociedade desde longa data por meio de movimentos específicos. No MST se apresenta a luta pela terra via Reforma Agrária e em outros movimentos. A participação da mulher no acesso à terra se fez nos moldes do Movimento e, atualmente, após assentadas as famílias, uma parte considerável das mulheres acaba por não participar ou o faz esporadicamente, pois a propriedade ocupa o tempo com a produção, os afazeres domésticos e os cuidados com os filhos. Fica claro, então, que os espaços institucionais e democráticos participativos da mulher nas políticas públicas e nos processos produtivos familiares com sustentabilidade se moldam e se limitam na lógica do modo de produção hegemônico do capital e encontram possibilidades de ruptura na luta pelo controle e pela efetivação dos direitos sociais e de propriedade.

As mulheres que mantêm a participação são as que já possuem filhos em idade de independência maior em relação a mãe, ou nos casos em que os esposos dividem os cuidados para que elas possam fazê-lo. Um avanço, nesse sentido, também pode-se considerar as cirandas das crianças, pois nesse caso as mães podem levar os filhos pequenos consigo nos eventos, nas reuniões e nas capacitações. Pode-se perceber, ainda, a participação ativa da maioria das entrevistadas na produção e organização do lote no Assentamento Valmir Mota de Oliveira.

Há, nesse sentido, que se realizar um trabalho de sensibilização para incentivar e fortalecer a participação da mulher no processo produtivo familiar com sustentabilidade. Embora não seja objeto deste trabalho, cabe destacar que esse processo seria importante por conta da mulher dar maior organicidade ao trabalho na propriedade, sendo necessário, para tanto, a participação dos profissionais em processos formativos e interventivos interdisciplinares, aqui referenciada a participação no M estrado em Desenvolvimento Rural Sustentável e a intervenção do Serviço Social, tanto em relação à posse da propriedade quanto no resgate das políticas para o meio rural.

Ao profissional de Serviço Social e ao Desenvolvimento Rural Sustentável (DRS), cabe delinear e viabilizar ações que possam fortalecer e ampliar a participação da mulher no processo de produção e comercialização da produção dos lotes rurais, participação contínua 
da mulher do campo na luta pelos direitos, efetivação e acesso às políticas a elas destinadas quer no Plano Nacional de Políticas para as Mulheres ou na Agenda 21. Dessa forma, promover-se-á a emancipação da mulher, alçando um processo mais igualitário de acesso e distribuição de bens e serviços e, consequentemente, a diminuição das desigualdades sociais e de gênero dentro do modo capitalista de produção e distribuição das riquezas, atingindo o desenvolvimento Rural Sustentável, garantindo os direitos humanos fundamentais dessas mulheres e suas famílias, garantindo-se a moradia, alimentação, água potável, enfim condições de vida digna.

\section{Referências}

BARRETO, M. P. S. L. Patriarcalismo e o feminismo: uma retrospectiva histórica. Ártemis, João Pessoa, v. 1, p. 64-73, 2004. Disponível em: http://periodicos.ufpb.br/ojs/index.php/artemis/article/viewFile/2363/2095. Acesso em: 1 nov. 2015.

BRASIL. Presidência da República. Plano nacional de políticas para as mulheres. Brasília, DF: Secretaria Especial de Políticas para as Mulheres, 2004. Disponível em: http://bvsms.saude.gov.br/bvs/publicacoes/pnpm_compacta.pdf. Acesso em: 5 ago. 2015.

BRUM ER, A.; ANJOS, G. Relações de gênero em assentamentos: a noção de empoderamento em questão. In: LOPES, A.; BUTTO, A. (ed.). Mulheres na reforma agrária, a experiência recente no Brasil. Brasília, DF: M inistério do Desenvolvimento Agrário, 2008. p. 217238.Disponível em: http://www.mstemdados.org/sites/default/files/1396-4020-1-PB.pdf. Acesso em: 8 ago. 2015.

CANDIDO, A. (org.). Sérgio Buarque de Holanda e o Brasil. São Paulo: Fundação Perseu Abramo,1998.

CARIGNANO, J. Valmir M ota em festa: a conquista da terra e dignidade. 2012. Disponível em: http://sitiocoletivo.blogspot.com.br/2012/10/valmir-mota-em-festa-conquista-daterra.html. Acesso em: 7 ago. 2015.

DEERE, C. D. Os direitos da mulher à terra e os movimentos sociais rurais na reforma agrária brasileira. Estudos Feministas, Florianópolis, v. 12, n. 1, p. 175-204, jan./abr. 2004. Disponível em: http://www.redalyc.org/articulo.oa?id=38112110. Acesso em: 4 jun. 2015.

DELGADO, G. Do capital financeiro na agricultura à economia do agronegócio: mudanças cíclicas em meio século (1965-2012). Porto Alegre: Editora da UFRGS, 2012.

DEM O, P. Participação é conquista: noções de política social participativa. 3. ed. São Paulo: Cortez, 1996. 
DIAS, M. O. L. S. Política e sociedade na obra de Sergio Buarque de Holanda. In: CANDIDO, A. (org.). Sérgio Buarque de Holanda e o Brasil. São Paulo: Fundação Perseu Abramo,1998.

FERNANDES, B. M. A judicialização da luta pela reforma agrária. In: SANTOS, J. V. T. (org.). Violências no tempo da globalização. São Paulo: Hucitec, 1999. Disponível em: file:///C:/Users/Usuario/Downloads/123223-231621-1-SM .pdf. Acesso em: 5 maio 2018.

FERNANDES, B. M. Questão Agrária: conflitualidade e desenvolvimento territorial. 2004. Disponível em:

http:// bibspi.planejamento.gov.br/bitstream/handle/iditem/564/Quest\%C3\%A30\%20agr\%C $3 \%$ Alria_conflitualidade $\% 20 \mathrm{e} \% 20$ desenvolvimento $\% 20$ territorial.pdf? sequence $=1 \&$ isAllowe $\mathrm{d}=\mathrm{y}$. Acesso em: 5 maio 2018.

HOLANDA. S. B. "RAIIZES DO BRASIL". 1979. São Paulo: Perspectiva.

LEFF, E. La apuesta por la vida: imaginación sociológica e imaginários sociales em losambientalesdelsur. M éxico: Siglo XXI Editores, 2014.

MEDEIROS, L. S. Assentamentos rurais e gênero: temas de reflexão e pesquisa. In: BUTTO, A.; LOPES, A. L. (org.). Mulheres na reforma agrária a experiência recente no Brasil. Brasília, DF: MDA, 2008. p. 9-18. Disponível em:

४ttp:// www.mda.gov.br/sitemda/sites/sitemda/files/user_arquivos_64/pageflip-420423274145-It_Mulheres_na_Reforma_A-1046705.pdf>. Acesso em: 14 ago. 2015.

M ONTAÑO, C.; DURIGUETTO, M . L. Estado, classe e movimento social. São Paulo: Cortez, 2010.

PASTÓRIO, I. T. A mulher no processo produtivo familiar com sustentabilidade no assentamento Valmir M ota de Oliveira - Cajati - Cascavel - PR. 2015. Dissertação (M estrado em Desenvolvimento Rural sustentável) - Universidade Estadual do Oeste do Paraná, Marechal Cândido Rondon, 2015.

PAULILO, M. I. M ovimentos das mulheres agricultoras e os muitos sentidos da igualdade de gênero. In: FERNANDES, B. M.; MEDEIROS, L. S.; PAULILO, M. (org.). Lutas camponesas contemporâneas: condições, dilemas e conquistas, v. 2: a diversidade das formas das lutas no campo. São Paulo: Editora UNESP; Brasília, DF: Núcleo de Estudos Agrários e Desenvolvimento Rural, 2009.

SCHWENDLER, S. F. A Participação da mulher na luta pela terra: dilemas e conquistas. In: FERNANDES B. M.; M EDEIROS, L. S.; PAULILO, M. I. (org.). Lutas camponesas contemporâneas: condições, dilemas, conquistas. São Paulo: Editora UNESP; Brasília, DF: Núcleo de Estudos Agrários e Desenvolvimento Rural, 2009.

SIM IONATTO, I. Gramsci: sua teo ria, incidência no Brasil, influência no serviço social. 4. ed. São Paulo: Cortez, 2011. 
SILVA, M . E. F. A (des) territorialização do povo Xukuru-Kariri e o processo de demarcação das terras indígenas no município de Palmeira dos Índios - Alagoas. 2004. Dissertação (Mestrado em Geografia) - Universidade Federal de Sergipe, Aracajú, 2004. Disponível em: http://indiosnonordeste.com.br/wp-content/uploads/2012/08/dissertacao_maria-ester.pdf. Acesso em: 5 ago. 2015.

SOUZA, M . R. A importância da posse da terra para o enfrentamento à feminização da pobreza no Assentamento São Manoel. In: FAZENDO GÊNERO, 8., 2008, Florianópolis. Anais [...]. Florianópolis, 2008. Disponível em:

http://www.fazendogenero.ufsc.br/8/sts/ST12/Marlene_Ricardi_de_Souza_12.pdf. Acesso em: 7 nov. 2015.

Recebido em:29/07/2018 Aceito em: 15/01/2019 